\title{
Mechanical characterization of rocks at high strain rate
}

\author{
E. Cadoni ${ }^{1}$, A.M. Bragov ${ }^{2}$, M. Dotta ${ }^{1}$, D. Forni ${ }^{1}$, A. Konstantinov ${ }^{2}$, and A. Lomunov ${ }^{2}$ \\ ${ }^{1}$ DynaMat Laboratory, University of Applied Sciences of Southern Switzerland, 6952 Canobbio, Switzerland \\ ${ }^{2}$ Research Institute of Mechanics, Lobachevsky State University, 603950 Nizhny Novgorod, Russia
}

\begin{abstract}
The paper presents the dynamic characterization in tension and compression of three rocks, Carrara marble, Onsernone gneiss and Peccia Marble, at high strain-rates. Two versions of a Split Hopkinson Bar have been used. The version for direct tension tests is installed at the DynaMat Laboratory of the University of Applied Sciences of Southern Switzerland, while the traditional version in compression is installed at the Laboratory of Dynamic Investigation of Materials of Lobachevsky State University. Results of the tests show a significantly strain-rate sensitive behaviour, exhibiting dynamic strength increasing with strain-rate. The experimental research has been developed in the frame of the Swiss-Russian Joint Research Program.
\end{abstract}

\section{Introduction}

The dynamic characterization of rocks under high loading rates is fundamental to understand the material behaviour in case of heavy earthquakes and dynamic events. The elaboration of the material constitutive law is of capital importance for the numerical simulations of the dynamic processes as those caused by earthquakes. These data are necessary and require experimental techniques able to induce on the rock materials state of loading reproducing the actual dynamic condition.

The dynamic characterization has been carried out by means of a traditional Split Hopkinson Pressure Bar (SHPB) and a Split Hopkinson Tensile Bar (SHTB) placed respectively at the Laboratory of Dynamic Investigation of Materials of Nizhny Novgorod and at the DynaMat laboratory of the University of Applied Sciences of Southern Switzerland. This equipment is briefly described and the results of dynamic tension/compression tests at different high strain-rates on several rocks (Carrara marble, Onsernone Gneiss and Peccia Marble) are discussed.

Thus, the objective of this work is the comparison between both tensile and compressive dynamic and quasistatic tests.

\section{Materials}

The analysed materials are two rocks from the Alps and the well known Carrara marble.

The alpine rocks are an orthogneiss from the Onsernone Valley and a Peccia marble from the Maggia Valley of the Canton Ticino (Switzerland). They belong to the group of the metamorphous rocks.

The petrography of the Onsernone orthogneiss is characterized by the presence of white feldspar (albite) and transparent quartz appear in the light minerals as well as a relatively large quantity of white mica (muscovite) and dark mica (biotite) are also included. The mean grain size of the crystals is about $0,5 \mathrm{~mm}$ while the maximum grain size is about $1 \mathrm{~mm}$ (see figure 1a) [1].

The two marbles are characterized by a granoblastic structures, the Peccia marble (see figure 1b) presents larger size of grain (about $1 \mathrm{~mm}$ ) respect to the Carrara marble (see figure 1c) having maximum grain size of about $0,2 \mathrm{~mm}[2]$.

In the case of orthogneiss materials, a series of cores have been drilled out in three directions with respect to the plane of schistosity: parallel $\left(\theta=0^{\circ}\right)$, perpendicular $\left(\theta=90^{\circ}\right)$, as well as at $\theta=45^{\circ}$. As result $\theta$ is then defined as the angle of schistosity with the loading direction as shown in figure 2.

The mechanical characteristics of the analysed materials are reported in the following table 1 [2].

\section{Experimental details}

Static and dynamic loading tests have been conducted using different experimental set-ups on cylindrical rock specimens with $20 \mathrm{~mm}$ in diameter and height/diameter ratio equal to 1 .

\subsection{Dynamic compressive and splitting tests}

Dynamic compressive and splitting tests were performed at the Laboratory of Dynamic Investigation of Materials in Nizhny Novgorod by means of a SHPB shown in figure 3.

The experimental set-up consists of a compact gas gun (1), incident (2) and transmitter (5) steel (or duralumin) pressure bars with the specimen (3) sandwiched between them. Power supply and calibration of strain gauges was produced by an original scheme (4). In order to record the electrical signals from strain gauges, a multichannel digital oscilloscope (6) was used. Diameters of striker as well as pressure bar are $20 \mathrm{~mm}$. The incident bar length was $1 \mathrm{~m}$, whereas the length of transmitter bar was $3 \mathrm{~m}$ in order to provide correct registration of possible additional cycles of loading during the experiment [3].

Strain pulses in the pressure bars during synchronization are shown in figure 4 . It can be seen that the force equilibrium is reached during the specimen loading. It can be also observed that the specimen destruction is reached just in the first cycle of loading. 
Table 1. Material properties.

\begin{tabular}{lccc}
\hline $\begin{array}{l}\text { Rock } \\
\text { material }\end{array}$ & $\begin{array}{c}\text { Onsernone } \\
\text { orthogneiss }\end{array}$ & $\begin{array}{c}\text { Peccia } \\
\text { marble }\end{array}$ & $\begin{array}{c}\text { Carrara } \\
\text { marble }\end{array}$ \\
\hline $\begin{array}{l}\text { Apparent } \\
\text { density }\left[\mathrm{kg} / \mathrm{m}^{3}\right]\end{array}$ & 2710 & 2706 & 2677 \\
\hline $\begin{array}{l}\text { Absolute } \\
\text { density }\left[\mathrm{kg} / \mathrm{m}^{3}\right]\end{array}$ & 2740 & 2795 & 2720 \\
\hline $\begin{array}{l}\text { Young's } \\
\text { modulus }[\mathrm{GPa}]\end{array}$ & $39,3(\theta=0)$ & 64,6 & - \\
\hline $\begin{array}{l}\text { Compression } \\
\text { strength }[\mathrm{MPa}]\end{array}$ & $\begin{array}{c} \\
203 \pm 0\end{array}$ & & - \\
\hline $\begin{array}{l}\text { Tensile } \\
\text { strength }[\mathrm{MPa}]\end{array}$ & $\begin{array}{l}12,6 \pm 0,1 \\
6,1 \pm 0,8\left(\theta=0^{\circ}\right)\end{array}$ & $87 \pm 8$ & $79 \pm 1$ \\
& $2,6 \pm 1,1\left(\theta=90^{\circ}\right)$ & & \\
\hline
\end{tabular}

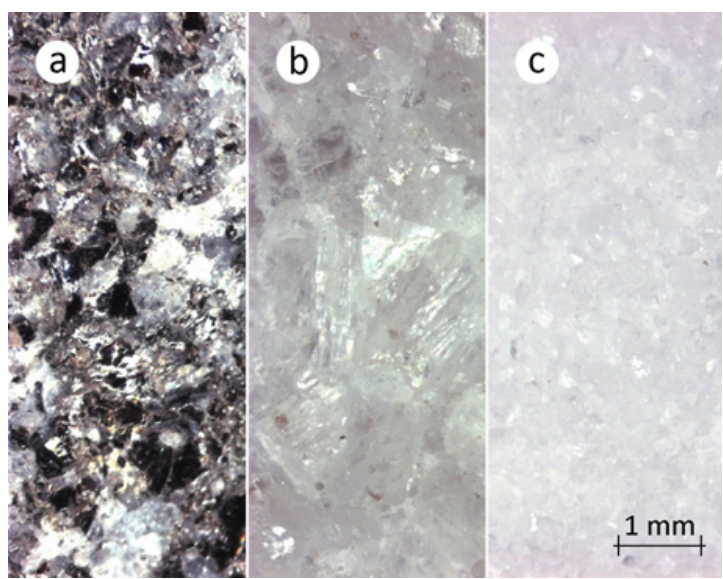

Fig. 1. Microcrystalline structure of the Onsernone Orthogneiss (a), Peccia marble (b) and Carrara marble (c).

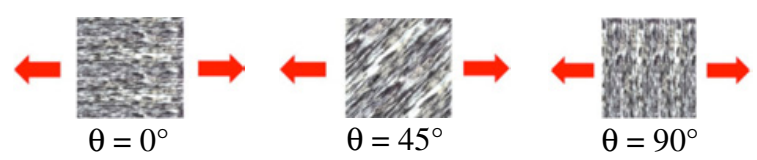

Fig. 2. Loading directions of schistosity [2].

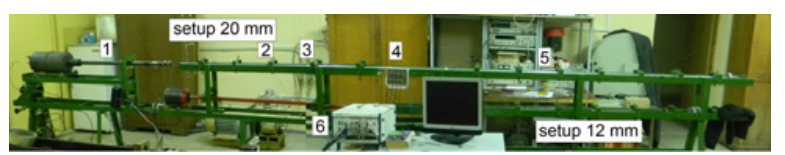

Fig. 3. Experimental apparatus realizing SHPB for compressive and splitting tests.

The point A located on the reflected indicates the beginning of specimen fracture as well as the increase of strain rate.

Splitting test of disks, also called 'Brazilian tests', is one of the available methods to measure the tensile strength of brittle materials [4]. Due to the stress-state of the disk, the failure is caused by tension when tensile stresses reach the tensile strength of the material on the diametric loading plane.

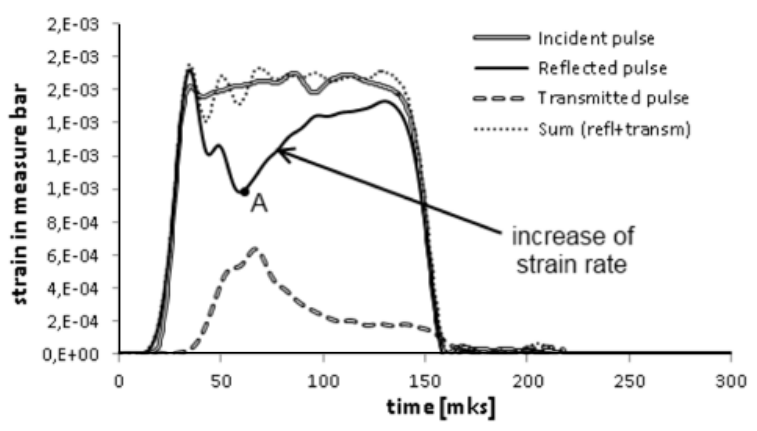

Fig. 4. Pulses during synchronisation.

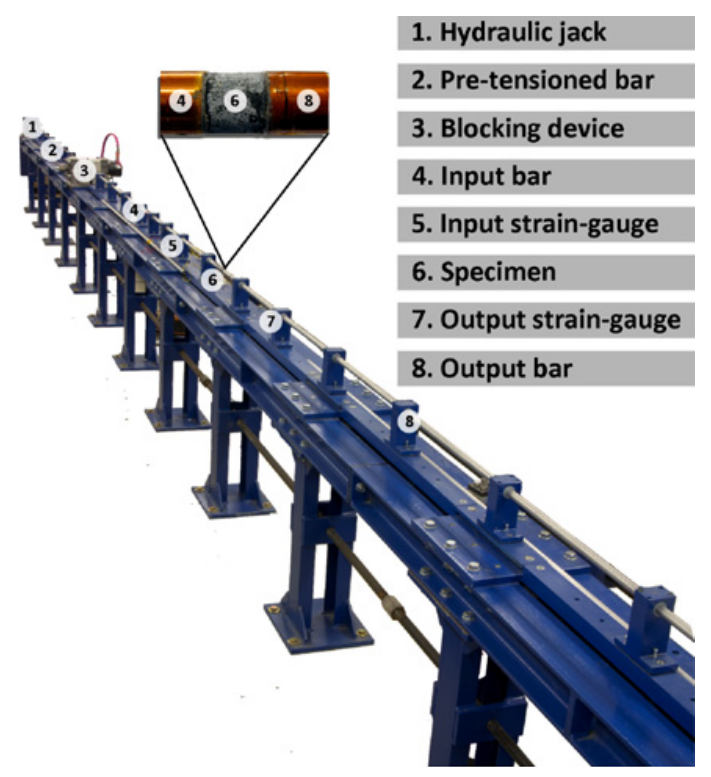

Fig. 5. Split Hopkinson Tensile Bar used in this research.

\subsection{Dynamic tensile tests}

\subsubsection{High strain-rate}

The high strain-rate tests in tension were performed using a Split Hopkinson Tensile Bar (SHTB) [1], that consists of two circular aluminium bars, called input and output bars, having a length of 3 and $6 \mathrm{~m}$ respectively, with a diameter of $20 \mathrm{~mm}$ to which the specimen is glued on using a bicomponent epoxy resin (see figure 5).

The input bar is connected with an high strength steel pre-tensioned bar $6 \mathrm{~m}$ in length, used as pulse generator with a diameter of $12 \mathrm{~mm}$ in order to obtain the same acoustical impedance of the input bar so that the pulse reflection, due to the interface, is avoided.

With reference of figure 5 a test with the SHTB is performed as follows [5]:

1. Firstly, a hydraulic actuator (1), of maximum loading capacity of $600 \mathrm{kN}$, is pulling the pretension high strength steel bar (2). The pretension stored in this bar is resisted by the blocking device (3).

2. Secondly, the rupture of a fragile bolt in the blocking device, gives rise to a tensile mechanical pulse of 2,4 ms with linear loading rate during the rise time, propagating along the input (4) and the output (7) bars bringing to fracture the specimen (6). 


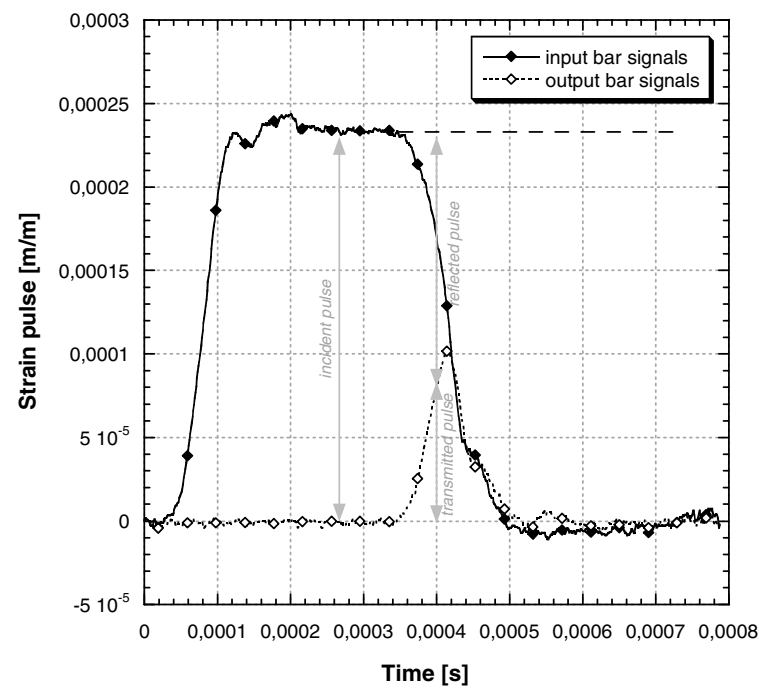

Fig. 6. Raw signals from SHTB.

As well as in the classical Hopkinson bar apparatus, the pulse propagates along the input bar with the elastic wave velocity equal to $C_{0}$, and constant shape. When the incident pulse $\left(\varepsilon_{I}\right)$ reaches the rock sample, it is partially reflected by it $\left(\varepsilon_{R}\right)$. On the other hand, the portion of the pulse that is not reflected, passes through the specimen $\left(\varepsilon_{T}\right)$ and propagates into the output bar, as shown in figure 5 .

The relative amplitudes of the incident, reflected and transmitted pulses depend on the mechanical properties of the specimen. With strain-gauges glued on the input and output bars ( $800 \mathrm{~mm}$ from the specimen) it is possible to measure the elastic deformation over time generated by the incident, reflected and transmitted pulses. The variable measures were registered by a 6 channels AlazarTech data acquisition system (ATS330). The system is designed to provide high precision (12 bit) waveform acquisition with a maximum $50 \mathrm{MS} / \mathrm{s}$ real-time sampling rate, $25 \mathrm{MHz}$ full power bandwidth and acquisition memory of $128 \mathrm{~K}$ samples per channel. Each individual board has its own independent trigger circuitry and time base, so that each channel can be recorded with different time windows. The data acquisition system receives the signals from the Pacific Instrument 6120 programmable transducer amplifiers. This is an expandable signal conditioning system which allows the user to configure each individual signal conditioner from any host computer with IEEE-488 or RS232 capability. Individual channels may be addressed, or on all channel command will simultaneously address all channels, for fast initial setup.

In figure 6, the raw signals measured on the input and output bars are represented. The clean resolution of the incident, reflected and transmitted pulses, the sharp rise time of the incident pulse, as well as the almost constant amplitude of the incident pulse can be observed.

Thereafter, the stress and strain in the sample can be derived from the following equations (1) and (2):

$$
\begin{gathered}
\sigma(t)=E_{0} \frac{A_{0}}{A_{S}} \varepsilon_{T}(t) \\
\varepsilon(t)=-\frac{2 \cdot C_{0}}{L_{S}} \int_{0}^{t} \varepsilon_{R}(t) d t
\end{gathered}
$$
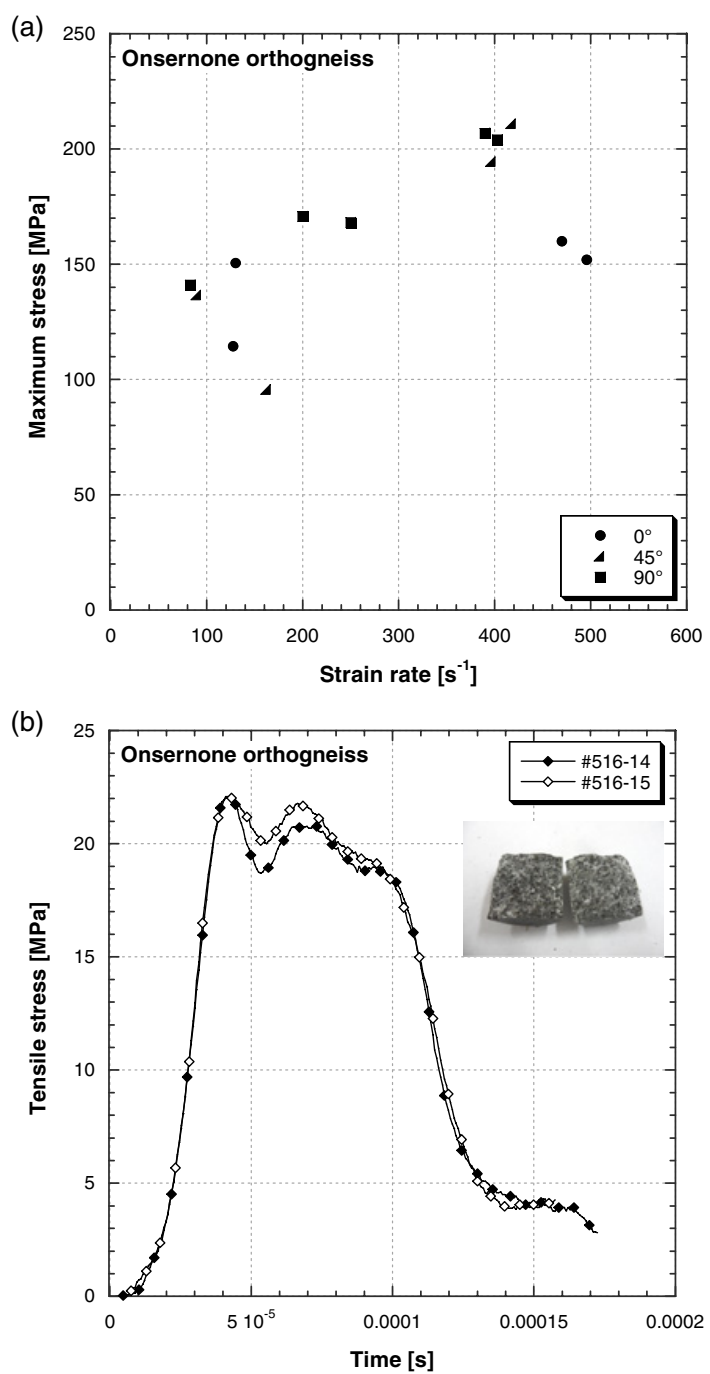

Fig. 7. (a) Compression strength of Onsernone orthogneiss. (b) Splitting behaviour of Onsernone orthogneiss.

where, $L_{S}$ is the specimen length, $A_{S}$ is the specimen crosssection area, $A_{0}$ is the output bar cross-section area, $E_{0}$ is the bar elastic modulus and $t$ is the time.

\section{Results}

\subsection{Compressive and splitting tests}

\subsubsection{Onsernone orthogneiss}

The compressive strength of the Onsernone orthogneiss rock considering the angle of schistosity with respect to the loading direction is shown in figure 7a.

Examples of tensile stress versus time behaviour (at similar conditions) of samples loaded at $\theta=45^{\circ}$ with respect to the schistosity plane are reported in figure $7 \mathrm{~b}$.

\subsubsection{Peccia marble}

The compressive strength of the Peccia marble as a function of the strain-rate is shown in figure $8 \mathrm{a}$. These points 

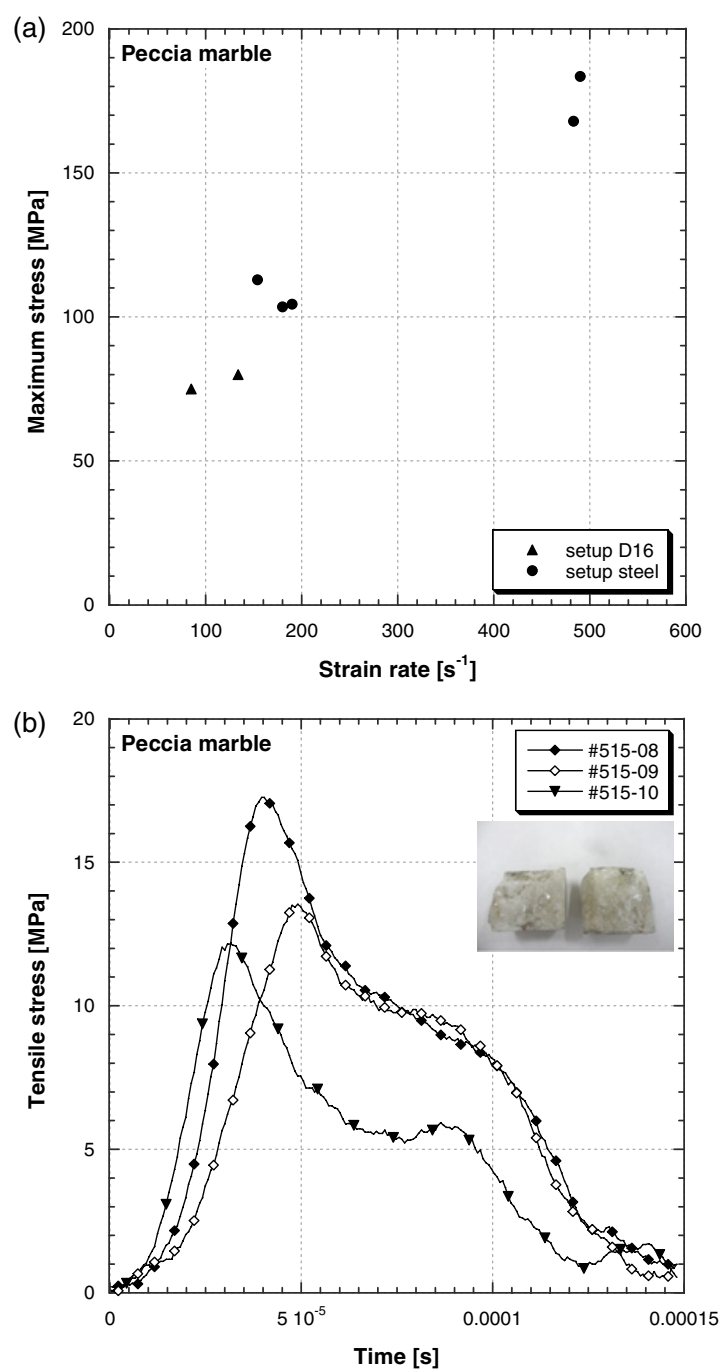

Fig. 8. (a) Compression strength of Peccia marble. (b) Splitting behaviour of Peccia marble.

were obtained as the maximum stress revealed in the stress versus strain curves measured during the dynamic compressive experiments.

In order to perform compressive tests at $100 \mathrm{~s}^{-1}$, duralumin pressure bars was used (set-up D16), whereas higher strain rates were obtained using a set-up with steel pressure bars (set-up steel).

Experimental results with three different striker velocities, 10,5 m/s (sample \#515-08), 13,5 m/s (sample \#51509) and 12,5 m/s (sample \#515-10) are reported in the following figure $8 \mathrm{~b}$.

\subsubsection{Carrara marble}

Compression experiments were produced using steel pressure bars $20 \mathrm{~mm}$ in diameter.

During experiments at strain-rate of about $200 \mathrm{~s}^{-1}$ specimens have been totally collapsed, while at $125 \mathrm{~s}^{-1}$, specimens fragmentation into a large pieces was observed. Stress versus strain curves in two loading conditions are depicted in figure 9 a.
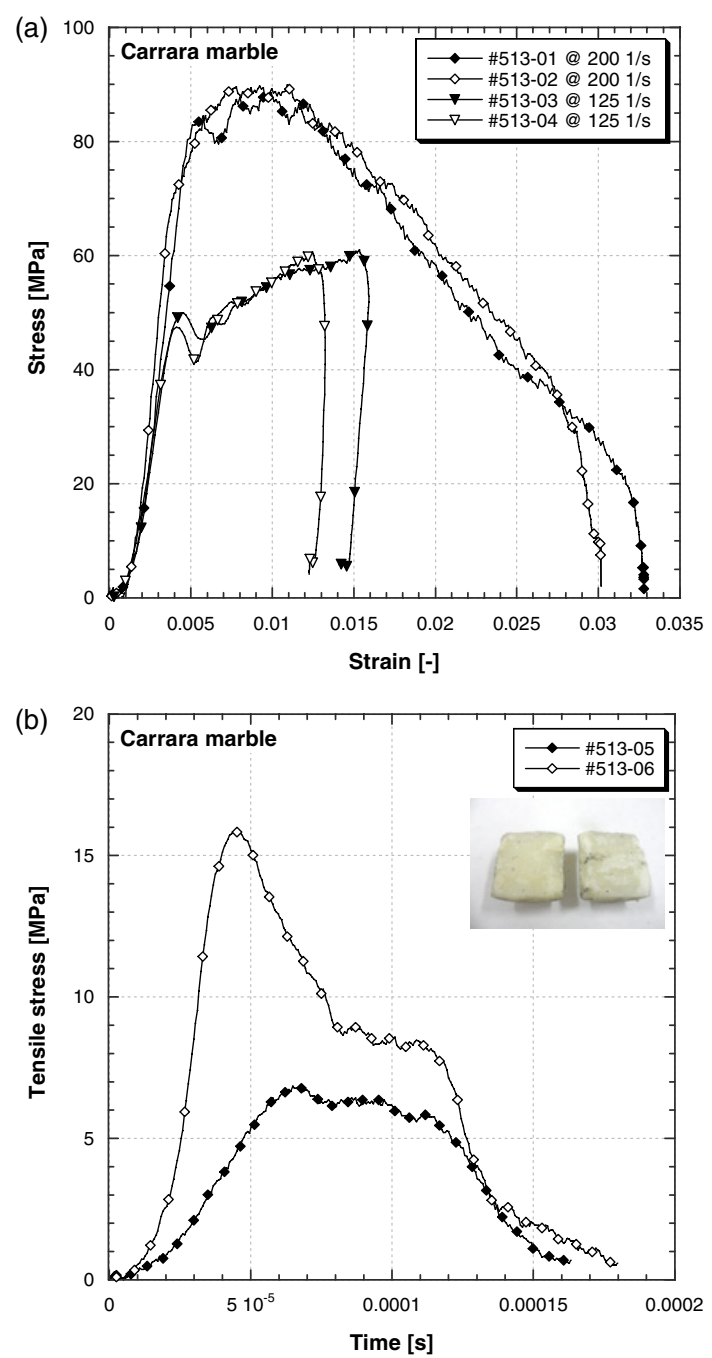

Fig. 9. (a) Compression behaviour of Carrara marble. (b) Splitting behaviour of Carrara marble.

Experimental results with two different striker velocities, 4,2 m/s (sample \#513-05) and 9,1 m/s (sample \#51306) are reported in figure $9 \mathrm{~b}$. These experiments were performed by using a duralumin pressure bars in order to register a small amplitude of transmitted pulse.

\subsection{Tensile tests}

All results of the tension tests at high strain rate carried out by the SHTB were performed keeping the preload constant $(18 \mathrm{kN})$ so that all rocks were tested under the same loading condition.

The results are collected in table 2 .

The tensile results reveal how at high strain rate all the mechanical properties are enhanced. The schistosity of the orthogneiss analysed influences the fracture behaviour. Fracture energy changes with the orientation of schistosity showing higher values for the $\theta=0^{\circ}$ and lower values for $\theta=90^{\circ}$.

An interesting parameter useful to describe the brittleness of this material is the characteristic length. As a unique material property, the characteristic length $1_{c h}=$ $\mathrm{G}_{F} \cdot E / f_{t}^{2}$ expresses fracture of concrete-like materials, 
Table 2. Results of the dynamic test in tension [2].

\begin{tabular}{lccc}
\hline Rock & $\begin{array}{c}\text { Tensile } \\
\text { material } \\
\text { Strength, } \\
\mathrm{f}_{t, d} \\
{[\mathrm{MPa}]}\end{array}$ & $\begin{array}{c}\text { Fracture } \\
\text { Energy, } \\
\mathrm{G}_{f, d} \\
{\left[\mathrm{~J} / \mathrm{m}^{2}\right]}\end{array}$ & $\begin{array}{c}\text { Stress } \\
\text { rate, } \\
\dot{\sigma} \\
{[\mathrm{GPa} / \mathrm{s}]}\end{array}$ \\
\hline Orthogneiss $\theta=0^{\circ}$ & $25.45 \pm 0.4$ & $1304 \pm 183$ & 1061 \\
Orthogneiss $\theta=45^{\circ}$ & $13.52 \pm 4.7$ & $868 \pm 397$ & 643 \\
Orthogneiss $\theta=90^{\circ}$ & $8.67 \pm 1.9$ & $712 \pm 81$ & 445 \\
\hline Peccia marble & $12.04 \pm 0.5$ & $355 \pm 46$ & 684 \\
\hline Carrara marble & $7.08 \pm 1.4$ & $380 \pm 56$ & 267 \\
\hline
\end{tabular}

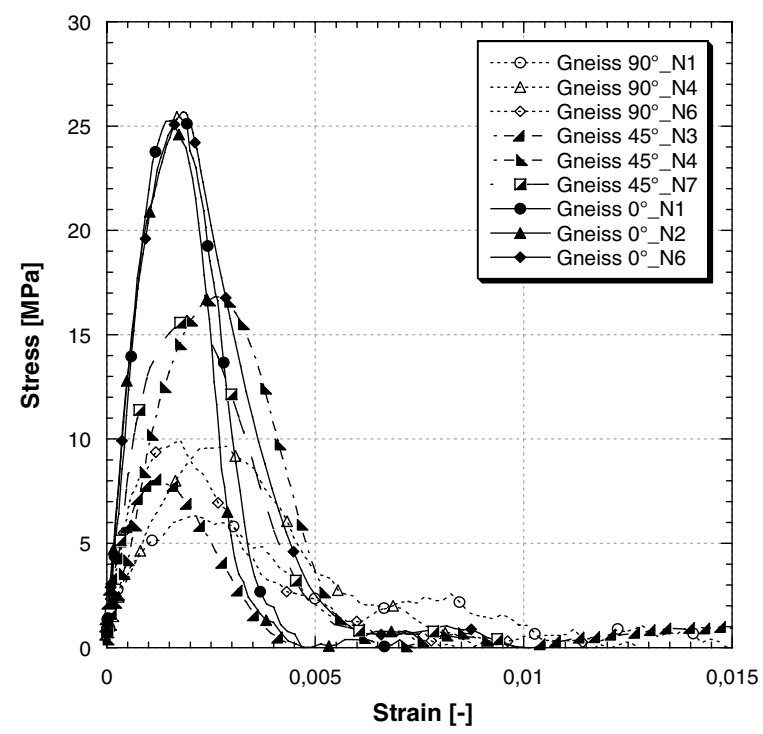

Fig. 10. Stress versus strain curves of Onsernone gneiss.

where is inversely proportional to the square of the tensile strength. This means that brittleness decreases with high fracture energy and increases with an increase in strength of material. The values at $\theta=0^{\circ}, \theta=45^{\circ}$ and $\theta=90^{\circ}$ are respectively $79 \mathrm{~mm}, 192 \mathrm{~mm}$ and $413 \mathrm{~mm}$ [1]. The lower value is for $\theta=0^{\circ}$ revealing less brittle behaviour with respect to the other two $\left(\theta=90^{\circ}\right.$ and $\left.\theta=45^{\circ}\right)$. The brittleness increases with the strain rate [1].

\subsubsection{Onsernone orthogneiss}

The behaviour in tension of the Onsernone orthogneiss is described by the stress versus strain curves (figure 10) for the same loading condition but at all three inclination of the schistosity.

\subsubsection{Peccia marble}

Peccia marble specimens were tested at high strain rate and the stress versus strain curves are depicted in figure 11.

\subsubsection{Carrara marble}

The stress versus strain curves of the Carrara Marble are shown in figure 12 .

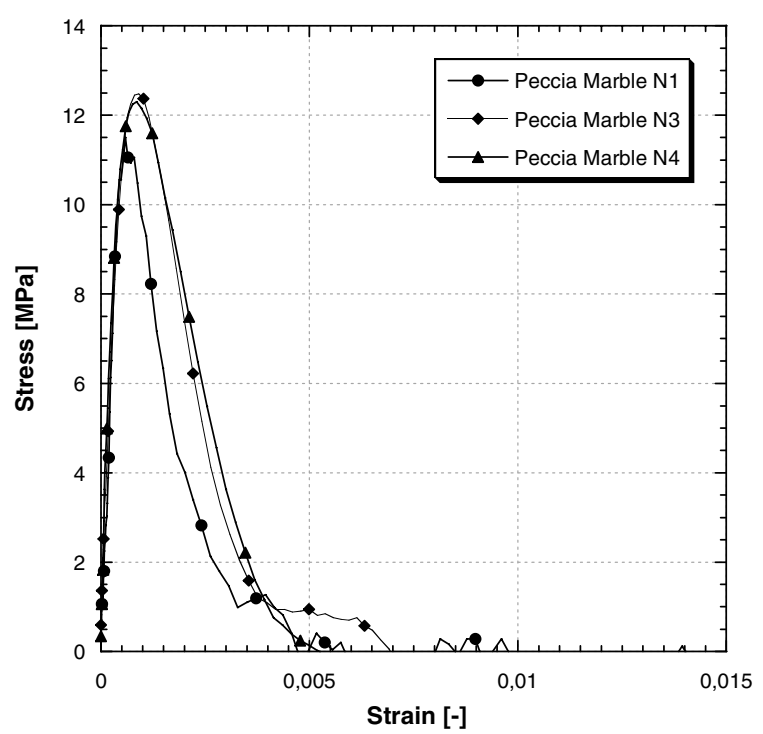

Fig. 11. Stress versus strain curves of Peccia marble.

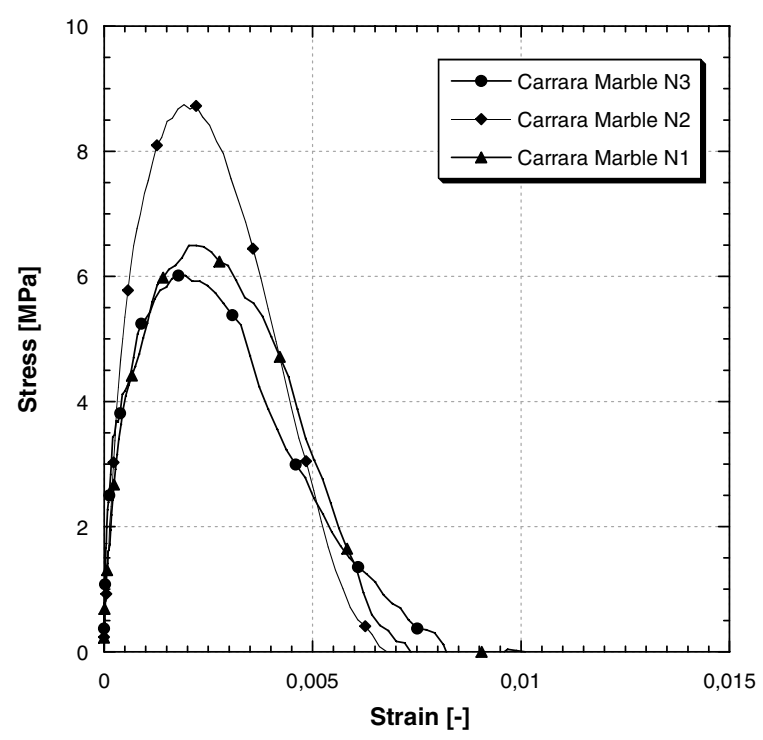

Fig. 12. Stress versus strain curves of Carrara marble.

In figure 13 is shown the comparison between the stress versus time curves obtained using two different tests to measure the tension strength at high strain rate. Brazilian test and direct tension test shown a good agreement considering that the stress rate is rather comparable.

\section{Concluding remarks}

Dynamic compression, indirect and direct tensile tests of an orthogneiss and two marbles were conducted using two set ups as Split Hopkinson Pressure Bar and Split Hopkinson Tensile Bar.

Results show that both compression and tensile strength are strain rate dependent. The influence of the orientation of schistosity for the orthogneiss analysed in tension and compression has been described.

It has been shown as the mechanical characterization of rock can be performed using the two experimental set ups here described. These results at high strain-rate are 


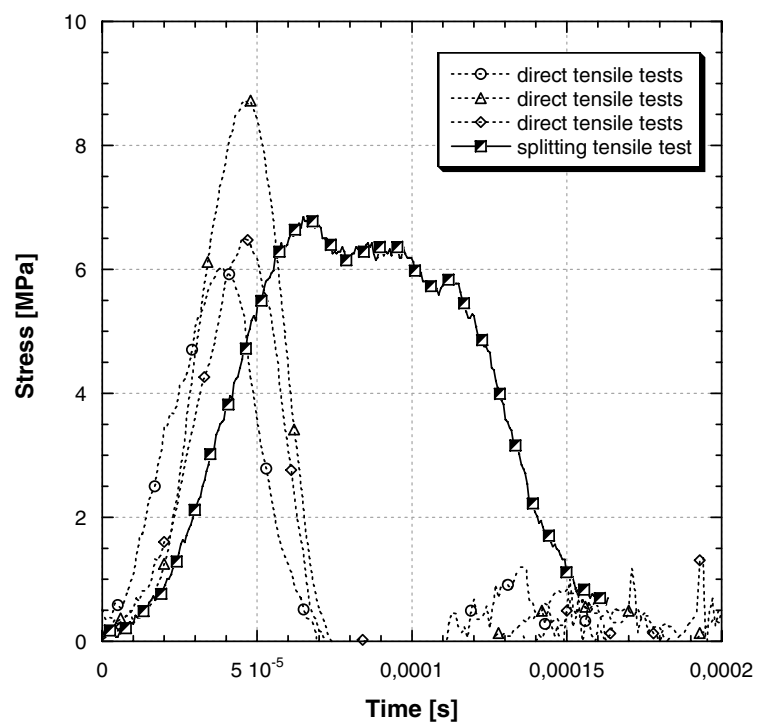

Fig. 13. Stress versus time curves of Carrara marble in tension using Brazilian and direct tension test.

fundamental for the construction of realistic constitutive relationships of the rock materials that are inserted in numerical code.

\section{Acknowledgements}

A special acknowledgement goes to the Scientific \& Technological Cooperation Programme Switzerland-Russia for the financial support of the Faculty Exchange Projects called "Teaching and Advanced Research on high strain rate behaviour of materials and testing" between DynaMat Laboratory of the University of Applied Sciences of Southern Switzerland and the Laboratory of Dynamic Investigation of Materials of Lobachevsky State University. Russian part of investigations was partially financed by RFBR (grant 10-01-00585).

\section{References}

1. E. Cadoni. Rock Mech. Rock Eng. 43 (2010) 43, 667676.

2. E. Cadoni, S. Antonietti, M. Dotta, D. Forni. Engg. Trans. 59 (2011), 197-210.

3. J. Rodriguez, C. Navarro, V. Sánchez-Gálvez, J. Phys. IV France, 04 (1994) 101.

4. Bragov, A.K. Lomunov, I.V. Sergeichev, J. Appl. Mech. Tech. Phys. 42 (2001).

5. A. Caverzan, E. Cadoni, M. di Prisco, Int. J. Impact Eng. 45 (2012), 28-38. 